\title{
Stone Composition, Metabolic Profile and the Presence of the Gut-Inhabiting Bacterium Oxalobacter formigenes as Risk Factors for Renal Stone Formation
}

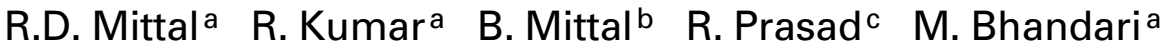 \\ Departments of a Urology and ${ }^{b}$ Genetics, Sanjay Gandhi Post Graduate Institute of Medical Sciences and \\ 'Geological Survey of India, Lucknow, India
}

\section{Key Words}

Hypercalciuria - Hyperoxaluria • Hypocitraturia •

Oxalobacter formigenes · Renal stones · Urolithiasis

\begin{abstract}
Objective: To examine stone composition, metabolic evaluation and colonization of Oxalobacter formigenes as risk factors for renal stone formation. Subjects and Methods: Eighty patients with renal stones and 70 healthy controls were enrolled in the study. Of the 80 patients, 48 were first-time stone formers (FSF) and 32 were 'recurrent' stone formers (RSF), recurrent indicating 2 or more episodes of stone formation. Stone analysis by X-ray crystallography, 24-hour urine metabolic profile and detection of $O$. formigenes-specific DNA by PCR were performed for each patient. Detection of $O$. formigenes was also performed on 45 and urinary metabolic profile on an additional 25 controls. Results: Calcium oxalate monohydrate was the major component of stones, hyperoxaluria and hypocitraturia were the most common urinary abnormalities in the 80 patients, $46 \%$ of RSF patients had hypercalciuria. Urinary abnormalities were far less frequent in the controls, with the exception of hypocitraturia (40\%). Of the urinary metabolites, only calcium levels were significantly different $(p<0.05)$ between FSF $(6.50 \pm 4.08 \mathrm{mmol} / 24 \mathrm{~h})$ and RSF $(8.21 \pm$
\end{abstract}

\section{KARGER}

Fax + 41613061234

E-Mail karger@karger.ch

www.karger.com

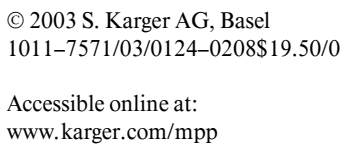

$5.26 \mathrm{mmol} / 24 \mathrm{~h}$ ) patients. Colonization of $O$. formigenes was higher in controls $(62.2 \%)$ than in FSF $(33.3 \%)$ or RSF $(28 \%)$ patients, it was least in patients with more than 4 episodes $(7 \%)$ of stone formation. Conclusion: The findings indicate that lack of colonization of $O$. formigenes may be an important risk factor for recurrence of stone formation (calcium oxalate monohydrate).

Copyright $@ 2003$ S. Karger AG, Basel

\section{Introduction}

Urolithiasis is a common disorder, affecting over $10 \%$ of the global population, with an incidence that varies from country to country [1]. The disease, which has a high incidence of recurrence following treatment, is one of the biggest challenges facing urologists today, partly due to the fact that the pathogenesis of the stone formation is not clearly understood $[2,3]$. Urolithiasis is a complex process influenced by several factors, including hyperoxaluria, hypercalciuria, hypocitraturia, hyperuricosuria, low urinary volume [4-6], anatomical malformations [7], and urinary stasis as well as dietary habits [8]. Recently, detection of Oxalobacter formigenes, a specific oxalate-degrading anaerobic bacterium inhabiting the gastrointestinal tracts of humans, has attracted attention because the absence of this bacterium appears to be a risk factor for
Dr. R.D. Mittal

Department of Urology, SGPGIMS, Raebareli Road

Lucknow-226014 (India)

Tel. +91522 668004 8/ext. 2116, Fax +91522 668017

E-Mailrmittal@sgpgi.ac.in 
development of hyperoxaluria and/or recurrent kidney stone disease [9].

Calcium oxalate and/or phosphate stones account for more than $80 \%$ of renal stones. It is increasingly believed that stone constituents along with metabolic abnormalities can be a valuable tool in predicting the risk of recurrence. Although stone analysis is not necessarily done as a routine procedure, it can provide important evidence for the metabolic basis of stone formation $[10,11]$. In this study, we sought to show how stone analysis using X-ray crystallography as well as metabolic and bacterial studies might reveal differences between first-time stone formers (FSF) and 'recurrent' stone formers (RSF), recurrent indicating 2 or more episodes of stone formation.

\section{Subjects and Methods}

Eighty stone formers attending the Department of Urology, Sanjay Gandhi Post Graduate Institute of Medical Sciences, Lucknow, India, from October 1999 to December 2001 were enrolled in the study. Their mean age was 39 years, ranging from 25 to 56 years; 70 were male and 10 were female. Of the 80 subjects, 48 were FSF (42 males and 6 females; mean age 35, range $25-50$ years. The remaining 32 subjects ( 28 males and 4 females; mean age 40 , range 29-56 years) were RSF, all of whom had 2 or more episodes of stone formation. None of the 80 patients included in the study had bowel disease, renal tubular acidosis or any urinary tract abnormalities.

\section{Controls}

Forty-five healthy staff members ( 30 males and 15 females; mean age 45, range 24-45 years) selected as controls were tested for the presence of $O$. formigenes. All of the 45 controls had not taken antibiotics 1 month prior to the start of the study. A 24-hour urine analysis was performed on an additional 25 healthy staff members ( 23 males and 2 females; mean age 42 , range $24-45$ years).

The study was approved by the institution's research and ethics committee. Informed consent was obtained from each subject.

\section{Stone Analysis}

Stones were collected from the 80 patients either by noninvasive methods or by open surgery and analyzed by X-ray crystallography. Stones were crushed to powder of nearly 200-300 meshes, filling in the rectangular groove of the sample holder. Phillips's X-ray Diffractometer was used to record the diffractograms using Fe Ka radiations on a vertical goniometer and the PW1710 system of the microprocessor [12].

\section{4-Hour Urine Analysis}

A 24-hour urine sample was collected from the 80 patients and 25 controls. The urine was collected in containers containing thymol as a preservative and was subsequently analyzed for urine volume, $\mathrm{pH}$ and excretion of ionic components such as oxalate, calcium, magnesium, citrate, phosphate, uric acid and creatinine. After taking an aliquot for creatinine and uric acid estimation, $10 \mathrm{ml}$ of concentrated $\mathrm{HCl}$ was added to the remaining urine, which was used for further assay. Oxalate was determined by the oxalate oxidase enzymatic method using kits from Sigma Diagnostics (St. Louis, Mo., USA); citrate was analyzed as described by Rajagopal [13]. Other biochemical parameters such as calcium, magnesium, creatinine, phosphorus and uric acid were assayed spectrophotometrically using kits from Chema Diagnostics (Jesi, Italy). Metabolic abnormality was assessed in terms of five categories: low urinary volume $(<1,500 \mathrm{ml} / 24 \mathrm{~h})$, hyperoxaluria $(>0.45 \mathrm{mmol} / 24 \mathrm{~h})$, hypercalciuria $(>7.5 \mathrm{mmol} / 24 \mathrm{~h})$, hypocitraturia $(<1.56 \mathrm{mmol} / 24 \mathrm{~h})$ and hyperuricosuria $(>4.46$ $\mathrm{mmol} / 24 \mathrm{~h}$ ). The statistical analysis of the urinary data was performed by Student's unpaired t test, and the frequency of each metabolite abnormality was compared by $\chi^{2}$ analysis.

\section{Detection of $\mathrm{O}$. formigenes}

Collection of Human Stool Samples. Fresh stool samples were supplied by each of the 80 subjects during their routine hospital admission or visit to the Urology Outpatient Department. Each of the 45 volunteers also supplied a fresh stool sample. Approximately 20-30 mg stool was collected as fecal swab using the Cary Blair media (Becton Dickinson, Franklin Lakes, N.J., USA) fecal collection and transport system.

DNA Extraction. Bacterial DNA was isolated directly from fresh stool within $2-3 \mathrm{~h}$ of sample collection using a slightly modified version of the procedure of Stacy-Phipps et al. [14]. Approximately 20$25 \mathrm{mg}$ of stool was suspended in $0.7 \mathrm{ml}$ of phosphate-buffered saline and centrifuged at 4,000 rpm for $1 \mathrm{~min}$ to remove the debris. The supernatant was centrifuged at $10,000 \mathrm{rpm}$ for $10 \mathrm{~min}$. The bacterial pellet was resuspended in $0.7 \mathrm{ml}$ of binding lysis buffer ( $5.3 \mathrm{M}$ guanidine thiocyanate, $10 \mathrm{~m} M$ DTT, $1 \%$ Tween $20,0.3 M$ sodium acetate and $50 \mathrm{~m} M$ sodium citrate) and incubated at $65^{\circ} \mathrm{C}$ for $15 \mathrm{~min}$. Glass matrix, $50 \mu$ (Bangalore Genei, India) was added to absorb DNA. The DNA was eluted from the glass beads with $10 \mathrm{~m} M$ TE buffer after a brief incubation at $50^{\circ} \mathrm{C}$.

Oligonucleotides. The genus-specific oligonucleotides for $O$. formigenes and Bac primers used for PCR were purchased from GIBCO-BRL (Bethesda, Md., USA). The oligonucleotide sequences used were as follows: OxF-6 3'-AATGTAGAGTTGACTGA-5'; OxF-7 3'-TTGATGCTGTTGATACG-5'; Bac-1 3'-AACTGGAGGAAGGTGGGGAT-5'; Bac-2 3'-AGGAGGTGATCCAACCGCA-5'; OxF-5 3'-GACAATGTAGAGTTGACTGATGGCTTTCATG-5'.

$P C R$. The PCR amplification was performed in 50- $\mu 1$ reaction mixtures containing 150-200 ng DNA, $200 \mu M$ dNTPs, $1 \mu M$ of each primer [OxF-6/OxF-7 (specific for the oxc gene of $O$. formigenes)], PCR buffer and 1.5 U Taq polymerase (Genetix). After initial denaturation $\left(94^{\circ} \mathrm{C}\right.$ for $\left.5 \mathrm{~min}\right), \mathrm{PCR}$ was carried out for 10 cycles of $94^{\circ} \mathrm{C}$ for $1 \mathrm{~min}, 59^{\circ} \mathrm{C}$ for $1 \mathrm{~min}$ and $72^{\circ} \mathrm{C}$ for $1 \mathrm{~min}$ followed by another 30 cycles with an annealing temperature of $55^{\circ} \mathrm{C}$ for $1 \mathrm{~min}$ in a thermocycler (Perkin Elmer 2400). The amplified PCR products were electrophorized in $1.2 \%$ agarose gels, visualized with UV light and documented (AlphaImager ${ }^{\mathrm{TM}} 1220$ Documentation and Analysis System, Alpha Innotech, San Leandro, Calif., USA). The PCR product of OxF-6/OxF-7 primers is $416 \mathrm{bp}$. Each set of PCR performed was controlled negatively using a reaction containing all the PCR components except for template DNA and positively using a reaction containing $O$. formigenes strain $O X B$ DNA as the template. Suitability of the DNA extracted was tested using Bac-1/Bac-2 primers (amplifies bacterial gene encoding 16S rRNA).

Southern Blot Analysis. Southern blotting was performed according to Sidhu et al. [15], with some modifications described as follows: 
Table 1. Stone composition (\%) in FSFs and RSFs

\begin{tabular}{lll}
\hline Composition & $\begin{array}{l}\text { FSF } \\
(1 \text { episode })\end{array}$ & $\begin{array}{l}\text { RSF } \\
\text { ( } \geq 2 \text { episodes }) \\
\mathrm{n}=32\end{array}$ \\
\hline Whewellite & 70.8 & 59.4 \\
Whewellite + weddellite & 18.6 & 21.9 \\
Whewellite + uricite & 6.3 & 6.3 \\
Whewellite + wedellite + uricite & 4.2 & 12.5 \\
\hline
\end{tabular}

Table 2. Frequency (\%) of urinary abnormalities in controls, FSFs and RSFs

\begin{tabular}{llll}
\hline $\begin{array}{l}\text { Urinary } \\
\text { abnormality }\end{array}$ & Controls & $\begin{array}{l}\text { FSF } \\
(1 \text { episode }) \\
\mathrm{n}=48\end{array}$ & $\begin{array}{l}\text { RSF } \\
(\geq 2 \text { episodes }) \\
\mathrm{n}=32\end{array}$ \\
\hline Hyperoxaluria & 10 & 58 & 68 \\
Hypercalciuria & 15 & 28 & 46 \\
Hypocitraturia & 40 & 88 & 76 \\
Hyperuricosuria & 0 & 7 & 6 \\
Hypomagnesuria & 7.6 & 30 & 20 \\
\hline
\end{tabular}

Table 3. Twenty-four-hour urinary metabolite excretion in controls, FSFs and RSFs

\begin{tabular}{lccc}
\hline Parameters & $\begin{array}{l}\text { Controls } \\
\mathrm{n}=25\end{array}$ & $\begin{array}{l}\text { FSF } \\
\mathrm{n}=48\end{array}$ & $\begin{array}{l}\mathrm{RSF} \\
\mathrm{n}=32\end{array}$ \\
\hline Urine volume, $\mathrm{ml}$ & $1,750 \pm 546$ & $2,546 \pm 1,177$ & $3,064 \pm 1,553$ \\
Oxalate, $\mathrm{mmol} / 24 \mathrm{~h}$ & $0.37 \pm 0.13$ & $0.65 \pm 0.33$ & $0.71 \pm 0.40$ \\
Calcium, $\mathrm{mmol} / 24 \mathrm{~h}$ & $4.76 \pm 2.83$ & $6.50 \pm 4.08^{*}$ & $8.21 \pm 5.26^{*}$ \\
Magnesium, mmol/24h & $3.84 \pm 0.38$ & $3.43 \pm 1.18$ & $3.84 \pm 1.23$ \\
Citrate, $\mathrm{mmol} / 24 \mathrm{~h}$ & $1.70 \pm 0.79$ & $1.23 \pm 1.24$ & $1.03 \pm 0.66$ \\
Creatinine, $\mathrm{mmol} / 24 \mathrm{~h}$ & $13.85 \pm 4.44$ & $14.93 \pm 12.90$ & $12.12 \pm 9.06$ \\
Uric acid, $\mathrm{mmol} / 24 \mathrm{~h}$ & $1.76 \pm 0.10$ & $2.17 \pm 1.19$ & $2.44 \pm 1.32$ \\
Phosphate, $\mathrm{mmol} / 24 \mathrm{~h}$ & $23.90 \pm 19.35$ & $24.43 \pm 35.21$ & $23.61 \pm 12.56$ \\
\hline
\end{tabular}

Statistical analysis performed by Student's t test; data are expressed as means SD. ${ }^{*} \mathrm{p}<0.05$. the size-separated PCR products were transferred onto positively charged nylon membranes (Boehringer Mannheim, Indianapolis, Ind., USA) followed by drying and UV cross-linking. The OxF-5 probe-sequence was end-labeled using $\gamma\left[{ }^{32} \mathrm{P}\right]$ dATP and T4 polynucleotide kinase. The membranes were prehybridized for $60 \mathrm{~min}$ at $58^{\circ} \mathrm{C}$ in hybridization solution ( $1 \%$ blocking reagent, $5 \times \mathrm{SSC}, 0.1 \%$ Sarkosyl, $0.02 \%$ SDS) and subsequently hybridized for $10-12 \mathrm{~h}$ at $58^{\circ} \mathrm{C}$ in fresh hybridization solution containing the labeled OxF-5 probe. Blots were washed under stringent conditions and exposed to X-Omat XK-5 film (Kodak) using an intensifying screen. The autoradiographs were analyzed for the presence or absence of $O$. formigenes.

\section{Results}

X-ray crystallographic results revealed that all the patients enrolled in the study had calcium oxalate monohydrate (whewellite) as a major component in the stones. Pure whewellite stone was found in $70.8 \%$ of the FSF patients and in $59.4 \%$ of the RSF patients. The remaining patients had mixed types of stones containing whewellite and weddellite (calcium oxalate dihydrate) and/or uricite (table 1).

Hypocitraturia was the most common abnormality found in these patients ( $88 \%$ in FSF, $76 \%$ in RSF), followed by hyperoxaluria (58 and 68\%, respectively). Hypercalciuria was markedly higher in RSF (46\%) than in FSF $(28 \%)$ patients. Far fewer patients had hyperuricosuria (7\% in FSF, $6 \%$ in RSF; table 2 ).

The mean oxalate levels were significantly higher in stone formers than in controls. When comparing FSF and RSF patients, the frequency of hyperoxaluria as well as mean oxalate excretion was not statistically significant, although differences in mean calcium excretion were statistically significant. While the frequency of hypercalciuria in FSF patients was remarkably lower (28\%) than in RSF patients (46\%), the difference was not statistically significant. Mean urinary magnesium and uric acid differences were not statistically significant between the two groups, as well as between the controls and stone formers $(\mathrm{p}>0.05)$. 


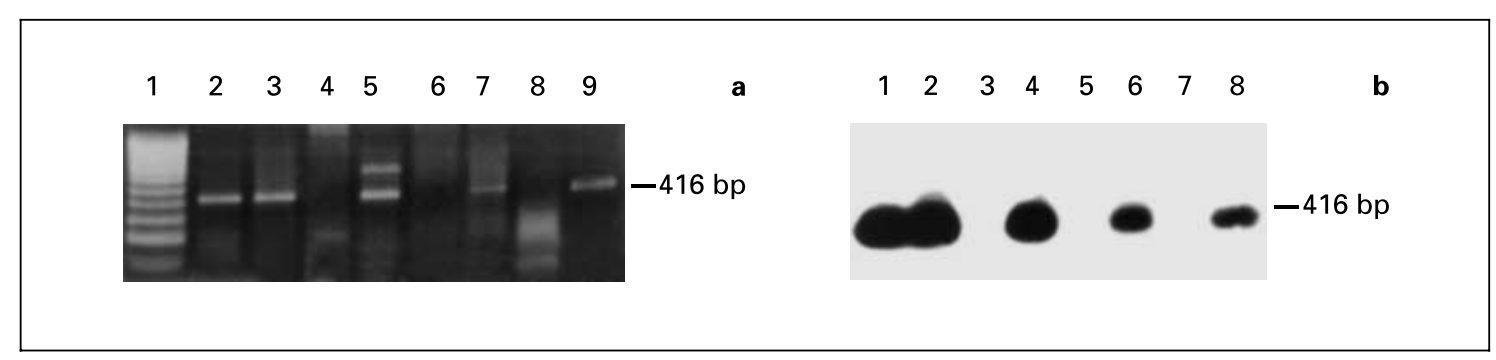

Fig. 1. a Detection of $O$. formigenes using a genus-specific primer (OxF6/OxF7) Lane 1: 100-bp ladder; lanes 2, 3, 5 and 7: presence of $O$. formigenes; lanes 4 and 6: absence of $O$. formigenes; lane 8: negative control; lane 9: positive control. b Southern blot analysis of above PCR products using genus-specific $\gamma-{ }^{32} \mathrm{P}$-labelled probe OxF-5.

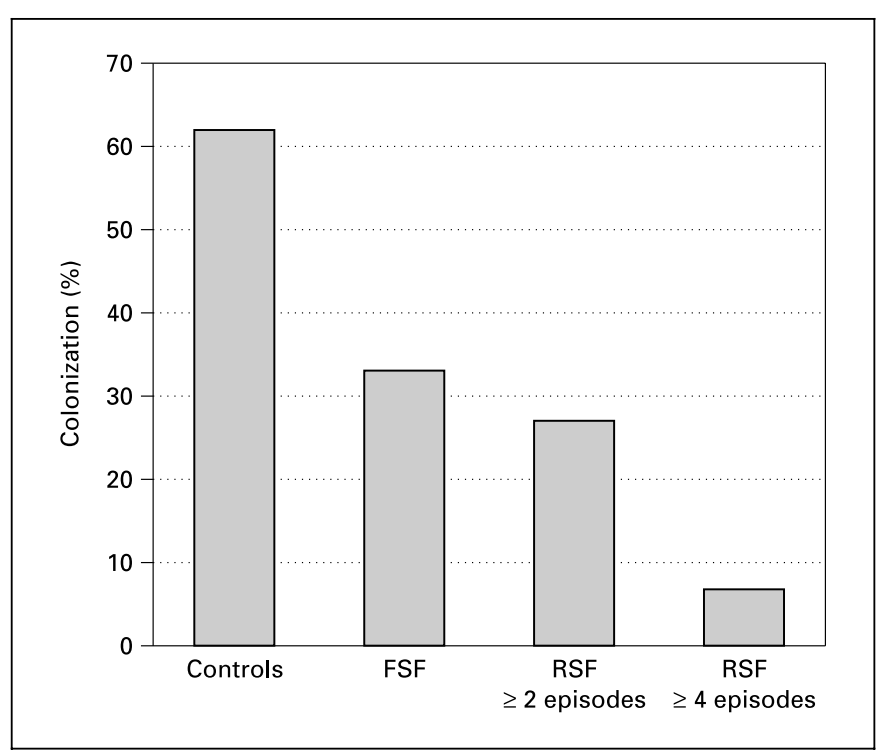

Fig. 2. Percent colonization of $O$. formigenes in controls, FSF, RSF and RSF patients with $\geq 4$ episodes of stone formation.

Mean oxalate, calcium and uric acid levels increased as the number of episodes increased, but a significant difference was only found in mean calcium levels $(\mathrm{p}<0.05)$. Citrate and phosphate levels decreased with the increasing number of episodes, but the difference was not significant (table 3).

The presence of $O$. formigenes in all the 80 stone formers and among the 45 controls is shown in figure $1 \mathrm{a}, \mathrm{b}$. Twenty-five of the 80 stone formers $(31.3 \%)$ were colonized with the bacteria compared to 28 of the 45 controls $(62.2 \%)$, a statistically significant difference $(\mathrm{p}<0.001)$. Of the 25 patients with $O$. formigenes colonization, 16

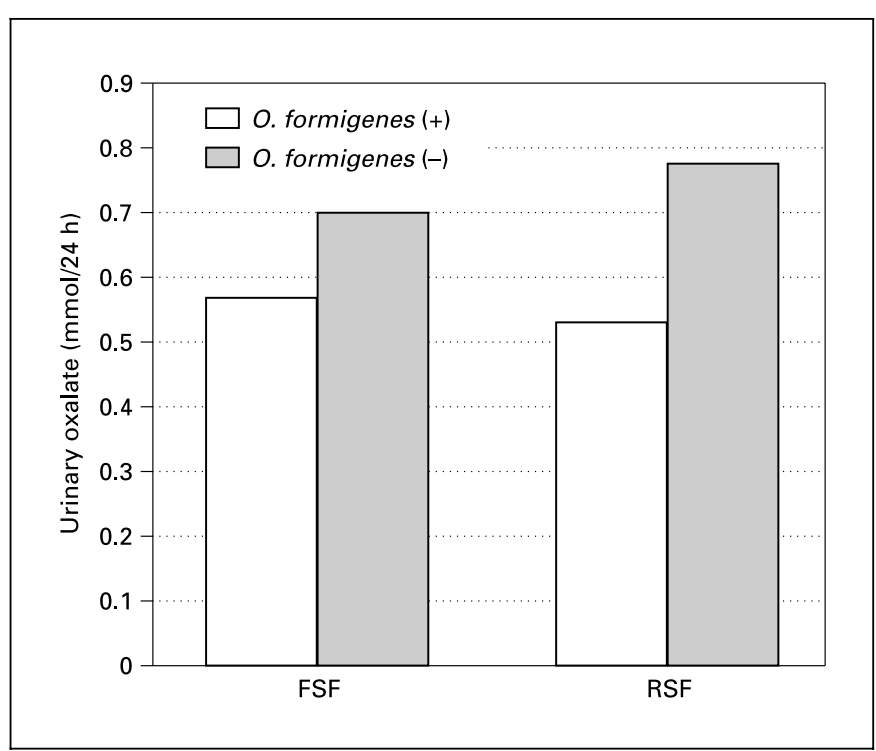

Fig. 3. Mean urinary oxalate levels in FSF and RSF with (+) and without (-) colonies of $O$. formigenes.

were FSF and 9 were RSF patients (fig. 2). Of the RSF study population $(\mathrm{n}=32)$, only 1 patient $(7 \%)$ was colonized with the bacteria (fig. 2), even though 14 of them had 4 or more episodes of stone formation.

The mean oxalate levels were higher in patients with $O$. formigenes than in patients without $O$. formigenes colonization. The difference was statistically significant in the RSF ( $p<0.05$ ) but not in the FSF group (fig. 3). In the RSF group, a significant difference in mean urinary oxalate levels between patients with and without colonization of $O$. formigenes $(\mathrm{p}<0.05)$ was observed, but no such significant difference was found in the FSF group (fig. 3). 


\section{Discussion}

Despite the introduction of non-invasive techniques for the removal of stones and the identification of several metabolic factors responsible for stone formation [4-6], stone recurrence continues to be a significant clinical problem [16]. About $80 \%$ of urolithiasis patients have been reported to have calcium oxalate stones [11]. In this study, we also observed a high incidence of calcium oxalate stone: $70.8 \%$ in FSF patients and $59.4 \%$ in RSF patients. Hypocitraturia was the most common abnormality in this study in both groups, consistent with previous reports [5, 17]. Although our data indicate that on the basis of urinary citrate levels, patients with recurrent stone formation cannot be distinguished from patients with 1 episode only, we can assume that urinary citrate is an important risk factor for stone disease.

Oxalate plays an important role in calcium oxalate stone formation. Although increased urinary oxalate depends upon the bioavailability of oxalate and calcium in the intestines, metabolic defects may also lead to high oxalate levels [18]. In recent years, the role of $O$. formigenes in regulating oxalic acid absorption in humans has attracted increasing attention due to its ability to maintain oxalic acid homeostasis [15, 19]. Previously, researchers faced difficulties culturing $O$. formigenes bacteria, but with the introduction of DNA-based PCR methods, it is now possible to detect $O$. formigenes in the feces and thereby correlate its level with urinary oxalate levels.

In the present study, the colonization of $O$. formigenes was much higher and statistically significant $(\mathrm{p}<0.001)$ in the controls than the stone formers. Sixty-two percent of the controls were observed to be colonized with this bacterium, whereas in the FSF and RSF patients, the colonization was in the range of 32 and $27 \%$, respectively. The most interesting observation was that among recurrent stone formers with $>4$ episodes, colonization with the bacteria was only $7 \%$. Patients without $O$. formigenes colonization also had higher urinary oxalate levels compared to the patients with $O$. formigenes colonization. Apparently, higher urinary oxalate levels could be due to absence of $O$. formigenes colonization, as reported earlier from our group [20]. Therefore it is likely that individuals without $O$. formigenes colonization are at a high risk of recurrent stone formation.

In the present study, decreased levels of citrate and increased levels of oxalate and calcium in the urine were found to be the major risk factors for urolithiasis, similar to previous reports [4-6]. The absence and/or low percentage of bacterial colonization, however, may be the major factor responsible for the recurrence of stone disease. Hence stone formers, particularly those lacking $O$. formigenes, may be advised to eat low oxalate food and use antibiotics judiciously. It is also assumed that oxalatedegrading bacteria are susceptible to antibiotics, gastric acidity and bile salts, any of which may act as barriers to the survival of the bacteria [21]. However, reduction of oxalate by recolonization with $O$. formigenes or through enzyme replacement therapy might provide effective therapy for the prevention of urolithiasis [19].

\section{Conclusion}

The findings show that comprehensive metabolic evaluation along with stone analysis and bacterial colonization status provide important information for the identification of risk factors in stone formation, facilitating the development of strategies for long-term prevention of recurrent stone disease. Lack of colonization of $O$. formigenes seems to be an important risk factor for recurrence of stone formation (calcium oxalate monohydrate).

\section{Acknowledgments}

This work was supported by grants from the Uttar Pradesh Council of Science and Technology and the Department of Science and Technology, Government of India. 


\section{References}

1 Bennani S, Debbagh A, Oussama A, el Mrini $\mathrm{M}$, Benjelloun S: Infrared spectrometry and urolithiasis. Report of 80 cases. Ann Urol (Paris) 2000;34:376-383 [in French].

2 Bek-Jensen H, Tisellius HG: Reported urine analysis in patients with calcium oxalate stone disease. Eur Urol 1998;33:323-332.

3 Pak CYC: Pathophysiology of nephrolithiasis; in Marberger M, Fitzpatrick JM, Jenkis AD, Pak CYC (eds): Stone Surgery. London, Churchill Livingstone, 1991, pp 259-300.

4 Borghi L, Meschi T, Amato F, Briganti A, Novarini A, Giannini A: Urinary volume, water and recurrence in idiopathic calcium nephrolithiasis: A 5-year randomized study. J Urol 1996; 155:839-843.

5 Cupisti A, Morelli E, Lupetti S, Meola M, Barsatti G: Low urine citrate excretion as main risk factor for recurrent calcium oxalate nephrolithiasis in males. Nephron 1992;61:73-76.

6 Levy FL, Adams-Huet B, Pak CY: Ambulatory evaluation of nephrolithiasis: An update of a 1980 protocol. Am J Med 1995;98:50-59.

7 Streem SB: Long-term incidence and risk factors for recurrent stones following percutaneous nephrostolithotomy or percutaneous nephrostolithotomy/extracorporeal shock wave lithotripsy for infection-related calculi. J Urol 1995; 153:584-587.

8 Goldfarb S: Dietary factors in the pathogenesis and prophylaxis of calcium nephrolithiasis. Kidney Int 1988;34:544-555.
9 Sidhu H, Enatska L, Ogden SD, Allison MJ, Peck AB: Evaluating children in the Ukraine for colonization with the intestinal bacterium Oxalobacter formigenes, using a polymerase chain reaction-based detection system. Mol Diagn 1997;2:89-97.

10 Balla AA, Salah AM, Khallab AH, Kambal A, Bonggartz D, Hoppe B, Hesse A: Mineral composition of renal stones from the Sudan. Urol Int 1998;61:154-156.

11 Ahlawat R, Goel MC, Elhence A: Upper urinary tract stone analysis using X-ray diffraction: Results from a tertiary referral center in Northern India. Natl Med J India 1996;9:1012.

12 Prasad R, Rai S, Kumar A: X-ray diffraction studies of kidney stones. Geol Surv India Spec Pub 1997;48:123-126.

13 Rajagopal G: A simple colorimetric procedure for estimation of citric acid in urine. Indian $\mathrm{J}$ Exp Biol 1985;22:391-392.

14 Stacy-Phipps S, Mecca JJ, Weiss JB: Multiplex PCR assay and simple preparation method for stool specimens detect enterotoxigenic Escherichia coli DNA during course of infection. J Clin Microbiol 1995;33:1054-1059.

15 Sidhu H, Holmes RP, Allison MJ, Peck AB: Direct quantification of the enteric bacterium Oxalobacter formigenes in human fecal samples by quantitative competitive-template PCR. J Clin Microbiol 1999;37:1503-1509.
16 Curhan G, Rimm E, Willett WC, Sampfer MJ: Regional variation in nephrolithiasis incidence and prevalence among United States men. J Urol 1994;151:838-841.

17 Tiselius HG, Berg C, Fornander AM, Nilsson MA: Effects of citrate on the different phases of calcium oxalate crystallization. Scanning Microsc 1993; 7:381-390.

18 Doane LA, Liebman M, Caldwell DR: Microbial oxalate degradation: Effects on oxalate and calcium balance in humans. Nutr Res 1989;9: 957-964.

19 Sidhu H, Schmidt ME, Cornelius JG, Thamilselvan S, Khan SR, Hesse A, Peck AB: Direct correlation between hyperoxaluria/oxalate stone disease and the absence of the gastrointestinal tract-dwelling bacterium Oxalobacter formigenes: Possible prevention by gut recolonization or enzyme replacement therapy. J Am Soc Nephrol 1999;10(suppl): S334-S340.

20 Kumar R, Mukherjee M, Bhandari M, Kumar A, Sidhu H, Mittal RD: Role of Oxalobacter formigenes in calcium oxalate stone disease: A study from north India. Eur Urol 2002;41:318 322.

21 Duncan SH, Richardson AJ, Kaul P, Holines RP, Allison MJ, Stewart CS: Oxalobacter formigenes and its potential in human health Appl Environ Microbiol 2002;68:3841-3847. 